\title{
Management of Rhynchophorus ferrugineus Olivier in the Gulf and Mediterranean region
}

\author{
C.P. Ramachandran ${ }^{1}$
}

\begin{abstract}
The red palm weevil Rhynchophorus ferrugineus Olivier is the most deadly and dangerous pest of coconut, date, oil, sago and other palms. R. ferrugineus is distributed in over 33 countries over a wide range of area under different agro-climatic conditions and attacks more than two dozen palm species. In the Middle East the weevil is the most destructive pest of the date palms. The hidden nature of the pest attack makes timely detection of the infestation and control measures difficult. The earlier reviews provide details of biology and control methods viz. phyto-sanitary and preventive, curative, biological, baiting and trapping etc. Different combinations of above mentioned control methods have also been tried with varying degrees of success. Results of two major IPM programmes carried out in the gulf countries, the first during 1993-1998 mainly based on chemical and pheromone trapping and the second from 1998-2002 using bio-agents and pheromone trapping are discussed. In Jordan valley intensive pheromone trapping and incorporation of systemic insecticide in irrigation water could not control the pest even after three years. Development of ecofriendly pest control strategies like hybrid sterility, incompatibility and disruption of tolerance to high temperatures in Gulf and Mediterranean regions is suggested to combat the pest.
\end{abstract}

Key words: Red palm weevil, Rhynchophorus ferrugineus, coconut palm, date palm, oil palm, sago palm, IPM, biological control, pheromone trapping, hybrid sterility.

\footnotetext{
${ }^{1}$ Retired Scientist, Central Plantation Crops Research Institute, Regional Station, Kayamkulam, Kerala, India. E-mail: captcpr@hotmail.com
} 


\section{Introduction}

Red palm weevil Rhynchophorus ferrugienus Olivier is a serious and dreaded pest of the coconut, date, oil and other cultivated palms. $R$. ferrugienus is distributed in over 33 countries and attacks more than two dozen palm species (Singh and Rethinam, 2005a, b). The red palm weevil is reported causing very severe damage to the date palm Industry. If the damage is allowed to continue without controlling it, date palm is under threat of extinction in the Gulf and the Mediterranean areas (Anonymous, 1998). Murphy and Biscoe (1999) and Singh and Rethinam (2005a) made an exhaustive review on the biology and prospectus of management of palm weevils. The hidden nature of the pest inside the stem with no external symptom at an early stage makes timely detection of the pest difficult. IPM programmes implemented in the Gulf area and some innovative methods of $R$. ferrugienus management are discussed.

\section{IPM programmes implemented in the Gulf area}

Two IPM programmes were implemented in the gulf area (Abraham et al., 1998; Anonymous, 1998). In the first IPM programme during 19931998 the following components were incorporated.

\section{Crop and field sanitation}

Destruction of affected palms, keeping the garden free of plant materials like cut petioles etc and destruction of unproductive palms whose crowns were cut.

\section{Trapping the weevil}

Trapping of the weevil using pheromone lures was carried out with three distinct objectives. (1) To monitor weevil activity and detect its presence in newer areas, (2) To mass trap the weevil and (3) to assess population levels of the pest. Monitoring traps were also used at a distance of $1 \mathrm{~km}$ to detect infestation. These traps were reported to attract more females and hence exert significant pressure on the population build up. It was admitted that pheromone traps will only partially suppress the pest besides indicating the presence of the weevil attacked palms in the surrounding area.

\section{Preventive chemical treatments}

Drenching of the palms from top to bottom was done with insecticides viz., chlorpyriphos, endosulfan and methidothion at 0.1 percent. During the fruiting period synthetic pyrethroid, deltamethrin/cypermethrin was preferred. The insecticides were sprayed at an interval of 2 months or so.

\section{Curative chemical treatment}

Slanting holes $5 \mathrm{~cm}$ diameter and $15 \mathrm{~cm}$ deep were made above the site of infestation into which the insecticide was poured and after a week the palm was checked for persistence of infestation. The insecticides used were pyrethrin-piperonyl butoxide, carbaryl, trichlorphone, endosulfan, dichlorovos etc. Fumigation of infested cavities with aluminium phosphide tablets was also attempted.

\section{Quarantine measures}

The movement of date palms as planting material from one area to other area may result in the transportation of pest infested palms. This maybe prevented by ensuring that palms are not infested and also restrict the movement of plants by strict quarantine laws.

The above operations were carried out relentlessly for a few years and could demonstrate that the pest could be kept under control. Large quantities of insecticides were used which posed a great threat to environment and man. The possibility of continuous use of insecticides will result in the development of resistance of the weevil to pesticides. The moment the pressure of control operations were lifted, the weevil population again started building up. 


\section{Second IPM programme in Gulf area}

The second IPM programme was started by Dr. Hanounik (Anonymous, 1998) and operated from 1998 to 2002. According to conservative estimates out of 50 billion date palms 300,000 of palms were affected by the weevil. Under the programme live tropical entomopathogenic nematodes which carry a deadly bacteria was injected into the trunks of infected palm trees. It was believed that the nematodes will remote sense the weevils, bore into them and release the deadly bacterium and kill the weevil in 72 hours. To go hand in hand with the above programme aggregation pheromone and kariomones to trap and kill the pest were also used. In India and elsewhere the control programme using nematodes and bacteria ended up with laboratory trials. The main difficulty in field trials was the inability of getting the nematodes to the weevil grubs harboured inside the stem. Monzer and Rahman (2003) reported the presence of ethanol, acetic acid; ethyl acetate etc generated during the degeneration of palm tissues infested by red palm weevil was harmful to Heterorhabditis. Based on their data they concluded that it will be difficult to control $R$. ferrugineus using $H$. Indica in the presence of these substances in palm trunks. A root injection of a suitable insecticide could give better results. Here again locating of the affected palm i.e. frequent monitoring of palms and gardens require manpower and money. Further, by the time the attack is detected the palm might be already dead.

The system of injection of the nematode by man in to the trunk may not be practical on a large scale field programme. Therefore the effort should be to locate a biological control agent which is host specific preferably from the gulf area and easily transmitted by the adult weevils from one palm to the other affected palm. Due to the above reasons the above IPM programme also could not do much in controlling the weevil.

Ferry and Gomes $(1998,2002)$ reported the spread of the pest to Spain, Israel, Jordan and Palestinian authority territories. In fact by now it is recorded in over 33 countries (Singh and
Rethinam, 2005a, b). In Jordan valley in Israel to control red palm weevil in a 450 ha plantation intensive trapping using 4,000 pheromone traps and confidor a systemic insecticide was incorporated along with irrigation water. Even after three years of the above control operations weevils were caught from the plantation.

\section{Other management options}

\section{Sterile Insect release method}

Rehalkar et al. (1973, 1977) and Ramachandran (1991) studied the effect of radiation on weevils. A radiation dose of $3 \mathrm{krds}$ on pupal and newly emerged adults resulted in complete sterility, but affected the mating ability of the males. Lower dose of radiation 1.5 krds gave 90 percent sterility initially but the weevils were found to regain fertility after some days. In the field experiment conducted in India (Rahalkar, 1977) the recaptured radiation sterilized males were found to produce viable eggs on mating with virgin females. Ramachandran (1991) studied the effect of radiation on $\mathrm{F} 1$ and $\mathrm{F} 2$ generation and reported that no deleterious effect of radiation is carried to next generation. The karyotype consisted of eleven pairs clearly showing X Y configuration (Hartlet, 1983). Testis squashes of pupae and adults revealed only spermatozoa, spermiocytes and a few metaphase stages only. No other meiotic stages could be recorded during different times of the day and night. The meiotic divisions take place at an earlier stage. Hence it is presumed that the effect of radiation reported immediately after treatment may be due to the inactivation of the sperms. Therefore, the question of using radiation sterilized males in weevil control does not arise. The above observations necessitate the need to develop other control strategies against the pest.

\section{Hybrid sterility}

Hybrid sterility has been reported in F1 and subsequent generations between crosses of closely related species or between different strains of the same species. In the case of 
Rhynochophorus the pest is spread over many countries under different ecological conditions. It is possible that these strains might have developed genetic changes. Ramachandran (1998) studied four populations of the weevil from different parts of India and found that strain variability exists between these populations and they constitute different strains of weevil. Recent findings indicate that changes occur at gene loci and its epistatic position (Allen et al., 2001). In Drosophila pseudoobscura, divergence of $\mathrm{X} \mathrm{Y}$ pairing region in mice (Matsuda et al. 1991) can cause isolation mechanism resulting in hybrid sterility.

The production of sterile hybrid is possible by hybridizing different strains of $R$. ferrugienus or closely related species. The closely related species of Rhynchophorus are $R$. ferrugienus, $R$. vulneratus, $R$. bilineatus, $R$. schach and $R$. palmarum (Wattanapongsiri 1966). Mating of $R$. ferrugienus and $R$. vulneratus under caged conditions was observed (Hallet et al., 1993). Therefore the production of sterile hybrids may not be a problem.

The weevil mates many times and the sperms of the latest mating are utilized to fertilise the egg (Rehalkar et al., 1973), which may be a constraint in the success of SIRM. Sterile hybrids normally show high vigour and they may be able to compete effectively with normal males. The higher ratio of sterile to wild males also affords superiority. Knippling (1960) had advocated that "release of just enough insects to reduce biotic increase rate by fifty percent during each generation in the first season and then the continuance of such rate of release each season might be more practical and economical way to achieve insect eradication than to release enough sterile insects to dominate the population by 90 percent or more during the first generation." The adult life span of the weevil is more than four months and successive releases of the sterile males will enable to maintain a higher proportion to normal males. The insect is amenable to mass breeding on artificial diet and sugarcane (Rahalkar et al., 1978).

\section{Ecological factors}

The weevil is distributed in different countries which fall between $45^{\circ}$ north and $15^{\circ}$ south latitude under different ecological conditions. The weevil has a wide host range, viz. coconut palm, date palm, oil palm, toddy palm, ornamental palms and other palms. In its distribution range the weevil is exposed to varying ambient temperatures ranging from $14^{\circ} \mathrm{C}$ to more than $50^{\circ} \mathrm{C}$. So far no detailed studies have been carried out on how the insect adapts to very high and low temperatures. All the life cycle studies were conducted under controlled conditions or in countries like India, Indonesia and Philippines, where the ambient temperature is less than $35^{\circ} \mathrm{C}$ or so. In one of the studies it was observed that the lethal temperature for eggs was $40^{\circ} \mathrm{C}$. The studies on larval and pupal period were carried out under controlled conditions of $25^{\circ} \mathrm{C}$ to $30^{\circ} \mathrm{C}$. El Ezaby (1997) in the course of studies on seasonal variation of population observed that the lower threshold for weevil was $12^{0} \mathrm{C}$ to $14^{0} \mathrm{C}$ on the basis of capture of weevils in traps during winter. The question of how the insect adapts to high temperatures i.e. the temperature maxima of $40^{\circ} \mathrm{C}$ and whether the same is due to genetic changes remains unanswered. Voleti et al. (1993) observed that the temperature variation due to transpiration loss of a plant leaf maybe $2^{0} \mathrm{C}$ to $3^{0} \mathrm{C}$ as compared to atmospheric temperature due to transpiration loss of temperature. Information on population fluctuation of the weevil in gulf countries indicated that population is low during the cool and hot months and the period in between marks high populations. The adaptability of the weevil to high temperatures can be utilized for its destruction. For this studies are to be carried out on the performance of $\mathrm{F} 1$ and subsequent generations by hybridizing adapted and non adapted weevils and back crossing the F1 and subsequent generations with parental populations and their performance under adverse temperature conditions evaluated. Once the adaptations are found to be genetical then the release of non temperature adapted male weevils can result in reduction of the weevil population in such areas. 


\section{References}

Abraham, V.A., Al Shuaibi, M.A., Faleiro, J.R, Abuzuhairah, R.A. and Vidyasagar, P.S.P.V. 1998. An integrated management approach for red palm weevil, Rhynchophorus ferrugineas Oliv., a key pest of date palm in the Middle East. Agric. Sci. 3: 77-84.

Allen, Orr. H. and Shannon Griving, 2001. Complex epistasis and genetic basis of hybrid sterility in the Drosophila pseudoobsecura Bogota-USA. Hybridisation Genetics 158: 1089-1100.

Anonymous, 1998. Slow death in Arabia: date palms face extinction. The Middle East, February 1998, pp. 49-50.

Avoleti, S.R., Kasturi Bai, K.V. Rajagopal. K. and Nambiar, C.K.B. 1993. Influence of soil type on the development of moisture stress in coconut (Cocos nucifera.L.) genotypes (1). Oleagineux 48(12): 505-508

El Ezaby, F.A. 1997. A biological in vitro study on the red Indian date palm weevil. Arab. J. Plant Prot. 15 (2): 84-87.

Ferry, M. and Gomes, S. 1998. The red palm weevil in the Mediterranean area. Palms 46: 4.

Ferry, M. and Gomez, S. 2002. The red palm weevil in the Mediterranean area. http://www.Palms.Org/Palmsjournal/2002/ red weevil/.html.

Hallet, R.H., Ochlschlager, A.C., Gries, G., Angerilli, N.P.D., Al Sharegi, R.K., Gassouma, M.S. and Borden, J.H. 1993. Field testing of aggregation pheromone of two Asian palm weevils, pp. 20-25. In: Proceedings Porium International Palm Oil Congress, September, Kuala Lumpur, Malaysia.

Hallett, R.H., Ochlschlager, A.C. and Borden, J.H 1999. Pheromone trapping protocols for the Asian Palm weevil, Rhynchophorus ferrugineus (Coleoptera: Curculionidae). Int. J. Pest Manage. 45(3): 231-237.
Hanounik, S.B. 1998. Steinenematids and Heterorhabditids as biological control agents for the red palm weevil (Rhynchophorus ferrugineus Oliv.) Sultan Qabus Univ. J. Sci. Res., Agricul. Sci. 3: 95-102.

Knippling, E.F. 1960. Use of Insects for their own destruction. J. Econ. Entomol. 53(3): 415-420.

Matsuda, Y., Hrobe, T. and Chapman. V.M. 1991 Genetic basis of X-Y chromosome dissociation and male sterility in inter specific hybrids. Proc. Nat. Acad. Sci. USA. 88(11): 4850-4854.

Monzer, A.E. and El Rahman, R.A. 2003. Effect on Heterorhabditis indica of substances occurring in decomposing palm tissues infested by Rhynnchophorus ferrugineus. Nematology 5(5): 647-652.

Murphy, S.T. and Briscoe, B.R. 1999. The red palm weevil an alien invasive: Biology and the prospects for biological control as a component of 1PM. BNI 20(1): 35-46

Rahalkar, G.W., Harwalkar, M.R., Rananavare, H.D., Kurian, C., Abraham, V.A. and Koya, K.M.A. 1977. Preliminary field studies on the control of the red palm weevil Rhynchophorus ferrugineus Oliv. (Pest of coconut and date palms in India) using radio sterilized males. J. Nucl. Agri. Bio. 6(3) 65-68.

Rahalkar, G.W., Harwalkar, M.R, Santharam, K and Gopal Ayengar, A.R. 1973. Laboratory studies on radiation sterilization of the red palm weevil Rhynchophorus ferrugineus Oliv. males. Indian Cocon. J. 9: 229-237 and 10: 2844.

Rahalkar, G.W., Tamhankar, A.J. and Santaram, K. 1978. An artificial diet for rearing Red Palm weevil Rhynchophorus ferrugienus Oliv. J. Plant. Crops 6(2): 61-64.

Ramachandran, C.P. 1991. Effect of gamma radiation on various stages of red palm weevil Rhychophorus ferrugineus Oliv. J. Nucl. Agri. Boil. 20(3) 218-231. 
Ramachandran, C.P. 1998. Biotypical variability among four populations of Red palm weevil Rhynchophorus ferrugineus Fab. I Oliv. from different parts of India. Cord 14(1): 26-41.

Singh, S.P. and Rethinam, P. 2005a.Trapping a major tactic of BIPM strategy of palm weevils. Cord 21(1): 57-83.

Singh, S.P. and Rethinam, P. 2005b. Semiochemicals as a valuable tool in BIPM of palm weevils. Cocoinfo International 12(1): 17-22.

Wattanapongsiri, A. 1966. A revision of the general Rhynchophorus and Dynamis (Coleoptera: Curculionidae). Bangkok, Thailand: Department of Agriculture Science Bulletin No. 1, 328 pp. 